\title{
Study of the Effectiveness of Switching-on LED Illumination Devices and the Use of Low Voltage System in Lighting
}

\author{
Aizhan Zhaparova, Dimitry Titov, Alexander Y. Baklanov \\ D. Serikbayev East Kazakhstan State Technical University Instrument \\ Engineering and Technology Automation \\ A.K. Protozanov Str. 69, 070004 Ust-Kamenogorsk, Kazakhstan \\ e-mail: \{azhaparova, dtitov, ABaklanov\}@ektu.kz
}

\section{György Györök}

Óbuda University, Alba Regia Technical Faculty

Budai út 45, H-8000 Székesfehérvár, Hungary

e-mail: gyorok.gyorgy@amk.uni-obuda.hu

Abstract: This paper considers the low-voltage system of lighting power supply with the possibility of integration with alternative energy sources without additional devices, such as voltage converters and generators, etc. using LEDs.

\section{Different Models of LED Lighting}

\subsection{Abilities of LED Power Provision}

Currently, modern lighting systems use energy-saving lighting elements, such as fluorescent lamps and light-emitting diode (LED) lamps. The most effective is the LED lighting system, which has high reliability and long service life (more than 50,000 hours). The classic circuit for switching on LED in lighting devices is shown in Figure 1. At figure $\mathrm{R}_{\mathrm{e}}$ there is an electronically controlled equivalent resistor $[1,3]$. 


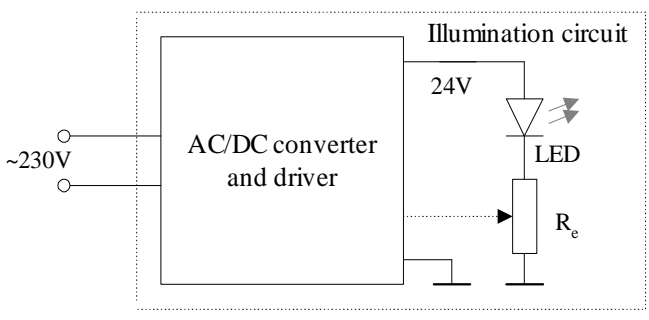

Figure 1

Typical circuit of LED illumination devices

One of the elements of an illumination device is the electric power supply, an AC/DC converter $[4,5]$. Thus, in lighting the room with a LED lamp connected to the circuit with $\mathrm{AC}$ voltage $230 \mathrm{~V}$, the loss of power when converting voltage by the driver as its efficiency factor is of course not equal to $100 \%$.

With wide integration of alternative energy sources, particularly in the case of solar batteries or solar cells for the use in standard illumination devices, it is necessary to convert the received direct current into alternating one as shown in Figure 2.

Typically, applying alternative energy sources already available illumination devices are used, schematically presented in circuit form 4 in Figure 1. And for supplying alternating voltage $230 \mathrm{~V}$, a converter $24-230 \mathrm{~V}$ is installed. Thus, the general scheme of implementation of LED lighting system connection might be presented in the form of Figure 3.

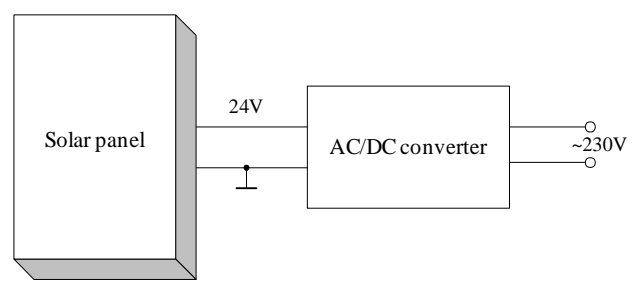

Figure 2

Scheme of converting from DC voltage of solar battery into alternating current

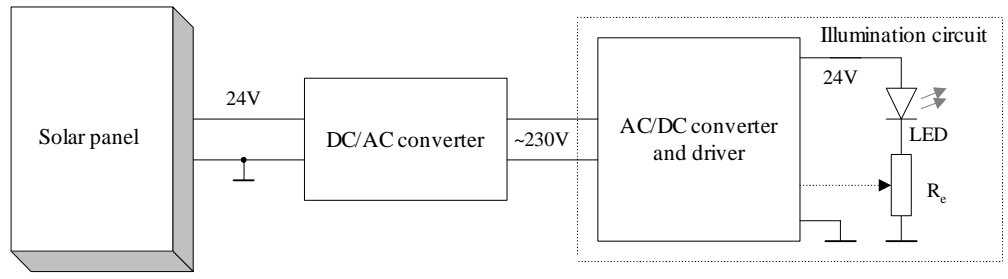

Figure 3

General scheme of implementation of an extant LED lighting system connection 


\subsection{Calculation of System Efficiency}

Despite the insignificant efficiency factor of solar batteries, their application is effective due to the use of renewable energy sources. However, in this scheme (see Figure 3) there are two converters and illumination circuit positions which introduce losses and electrical leaks in the lighting system. The first converter converts the direct current produced by the solar panels of $24 \mathrm{~V}$ into operating voltage of $230 \mathrm{~V} \mathrm{AC}$, and the second converter (AC/DC converter) converts $\mathrm{AC}$ to DC from $230 \mathrm{~V}$ to $24 \mathrm{~V}$.

To determine the efficiency of implementing double conversions of current we need to calculate the efficiency factor of the system [2].

The conversion ratio (efficiency factor) of the converter is characterized by the ratio of the active power supplied to the load to the total power consumed by the conversion device.

The conversion ratio (efficiency factor) of the conversion device is determined by formula:

This is an equation example:

$\eta=\frac{P_{d}}{P_{d}+\Delta P}$

where $\mathrm{P}_{\mathrm{d}}$ : power, consumed by the electric motor of the converter:

$P_{d}=\frac{P_{d . n o m}}{\eta}$,

where: $\mathrm{P}_{\mathrm{d} \text {.nom }}$ is the nominal value of the electric motor power of the converter and $\Delta \mathrm{P}$ is the total power loss in the converter. Total power losses in the converter are determined according to equation (3):

$$
\Delta P=\Delta P_{B}+\Delta P_{c o n t}+\Delta P_{t r},
$$

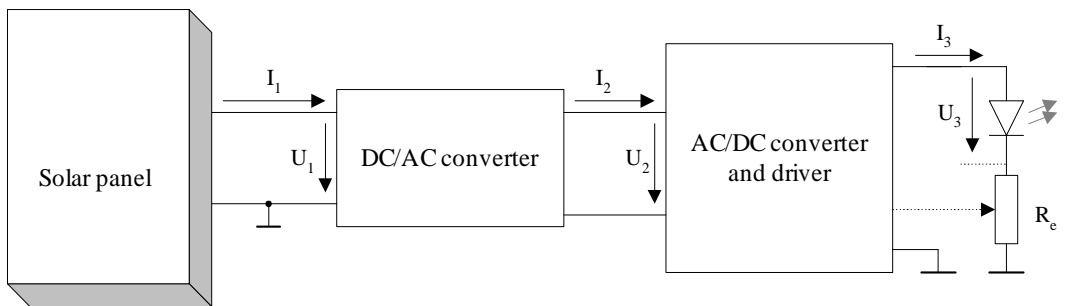

Figure 4

General scheme for measuring the efficiency factor of the system

where $\Delta \mathrm{P}_{\mathrm{B}}$ : is the loss in rectifying elements of the converter in (4): 


$$
\Delta P_{B}=n \Delta U_{c} I_{a},
$$

where $\mathrm{n}$ : is a number of rectifying elements in a rectifier circuit of the converter and $\Delta \mathrm{U}_{\mathrm{c}}$ : is the direct voltage loss in the rectifying elements of the converter, $\mathrm{I}_{\mathrm{a}}$ : is an average number of current in the rectifying element of the converter, and $I_{a}=I_{\text {d.nom }} / 3, I_{d . n o m}$ : is the value of nominal current of the converter motor, $\Delta P_{\text {cont }}$ : is the consumed power by the controlling system. It is possible to define a heuristically value; $\Delta \mathrm{P}_{\text {cont }} \sim 0,005 \cdot \mathrm{P}_{\text {d.nom. }}$. The losses in transformer (5):

$$
\Delta P_{t r}=\Delta P_{s t}+\Delta P c \text {, }
$$

where $\Delta \mathrm{P}_{\mathrm{st}}$ : losses in supply transformer. $\Delta \mathrm{P}_{\mathrm{c}}$ is a loss, determined by formula (6):

$$
\Delta P c=\Delta P_{s c} \frac{I_{2}}{I_{2 . \text { nom }}},
$$

where $\mathrm{P}_{\mathrm{sc}}$ is the short-circuit power, $\mathrm{I}_{2}$ : actual value of the operating currents of secondary winding. $\mathrm{I}_{2 \text { nom }}$ : current of valve-side winding $[1,2,6]$.

To study the effectiveness of a low-voltage power supply circuit based on the use of solar batteries, we carried out measuring operations for determining the efficiency factor of the DC/AC and the AC/DC converter. The general scheme for measuring the efficiency factor of the system is shown in Figure 4. The general view of the assembled system for measuring operations is shown in Figure 5.

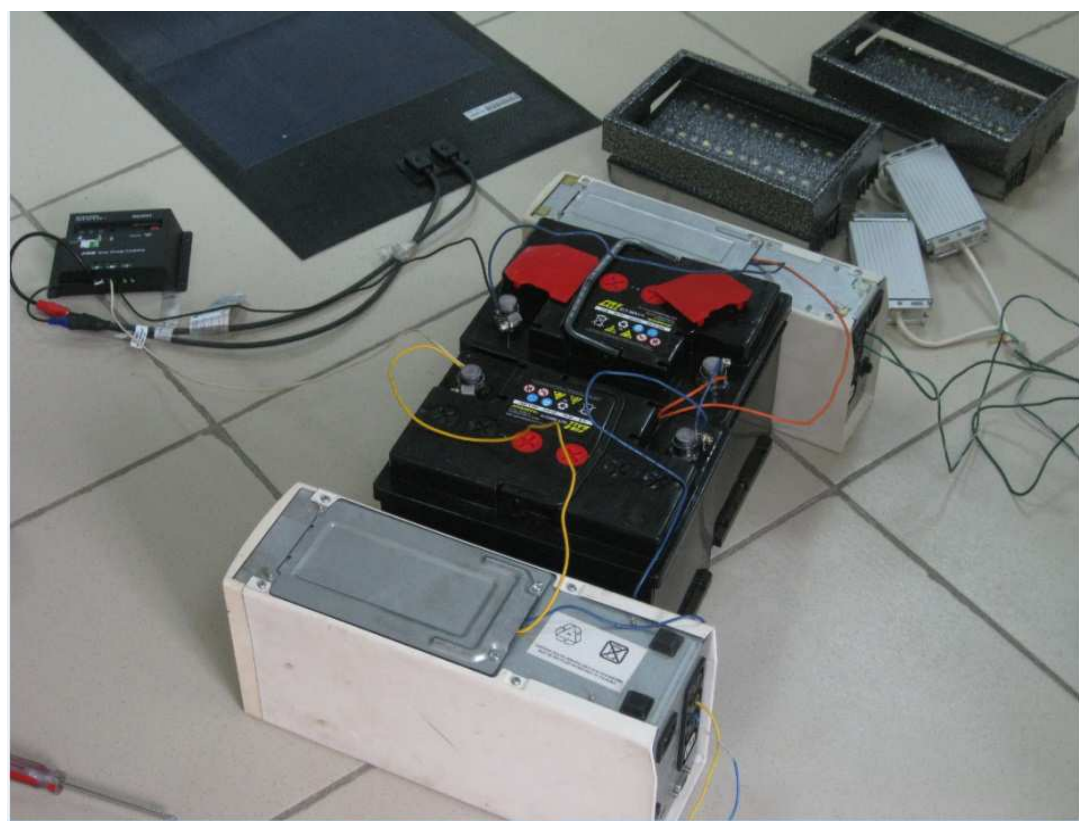

Figure 5

General view of the lighting system assembled in test mode 


\subsection{Calculation of System Efficiency}

The efficiency factor characterizes system efficiency of any device with respect to power conversion or transmission. It is determined by the ratio of effective energy used to the total amount of energy received by the system. The efficiency factor is a dimensionless quantity and is often measured in percentage and denoted by $\eta$ [10]. By energy conservation law, the efficiency factor is always less than one or equal to it. Let us consider the general scheme of measuring the efficiency factor of the DC/AC converter and AC/DC converter in Figure 4. Supposing that the $\mathrm{P}_{1}$ $\left(\mathrm{U}_{1}, \mathrm{I}_{1}\right)$ value of DC/AC converter is basic. $[7,8,11]$. On the output of the DC/AC converter $\mathrm{I}_{2}$ and $\mathrm{U}_{2}$ are measured, which are necessary for the calculation of load power consumption $\mathrm{P}_{2}$ from the voltage converter. We determine the efficiency factor of the converter $\eta_{1}$ by formula (7):

$\eta_{1}=\frac{P_{2}}{P_{1}}$,

This formula (8) defines the actual efficiency factor of the voltage converter. The power of the converter 3 (AC/DC converter) Figure 3, is determined by the following formula (8) correspondingly:

$\eta_{2}=\frac{P_{3}}{P_{2}}$,

The summarized total efficiency factor $\Sigma \eta$ of the converters can be defined by formula (9):

$\Sigma \eta=\eta_{1} \eta_{2}$

The module of uninterruptible power supply APC Back-UPS was used for converting the low voltage potential difference, shown in Figure 6 and for converting AC to DC as shown in Figure 7.

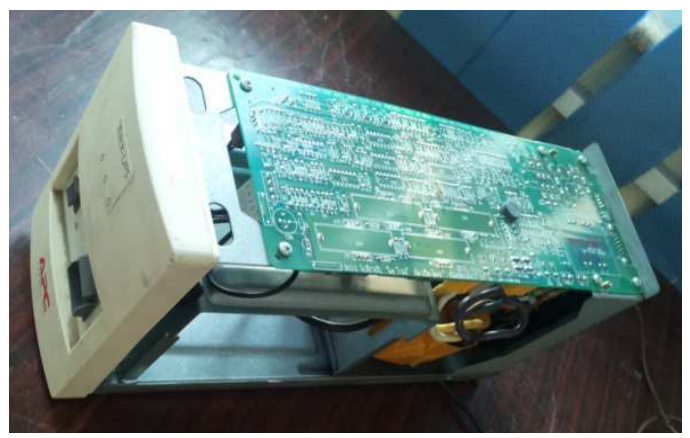

Figure 6

An uninterruptible power supply as a DC/AC converter 


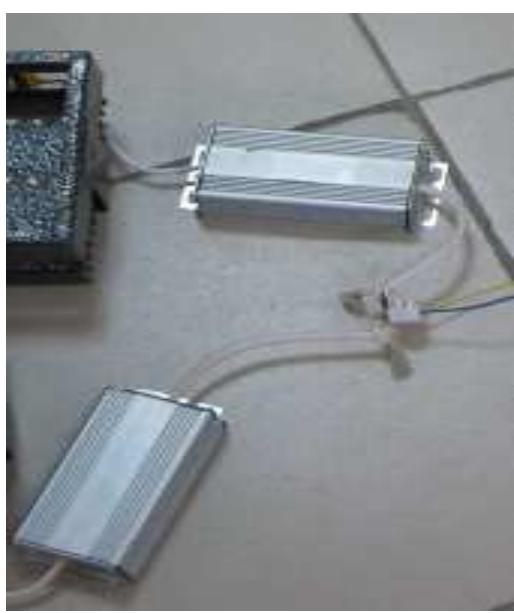

Figure 7

Exterior appearance of the voltage converter from $230 \mathrm{~V}$ to $24 \mathrm{~V}$

The values of currents and voltage measured according to scheme 4 are listed in Table 1.

Table 1

Experimental values of currents and voltage at different power

\begin{tabular}{|c|c|cc|c|c|c|c|c|}
\hline $\mathrm{I}_{1}[\mathrm{~A}]$ & $\mathrm{U}_{1}[\mathrm{~V}]$ & $\mathrm{P}_{1}[\mathrm{~W}]$ & $\mathrm{I}_{2}[\mathrm{~A}]$ & $\mathrm{U}_{2}[\mathrm{~V}]$ & $\mathrm{P}_{2}[\mathrm{~W}]$ & $\mathrm{I}_{3}[\mathrm{~A}]$ & $\mathrm{U}_{3}[\mathrm{~V}]$ & $\mathrm{P}_{3}[\mathrm{~W}]$ \\
\hline 2,2 & 12,6 & 27,7 & 0,06 & 207 & 11,1 & 0,14 & 37,6 & 5,3 \\
\hline
\end{tabular}

As a result of the study and calculations, the efficiency factor of the DC/AC converter in Figure 4 is 40,1\% and the efficiency factor of the AC/DC converter in Figure 4 is $48 \%$. The summarized efficiency factor is $20 \%$. This shows a very low efficiency of the application of this scheme. The usage of solar batteries and systems without current converters (Figure 8) presents an important perspective [9].

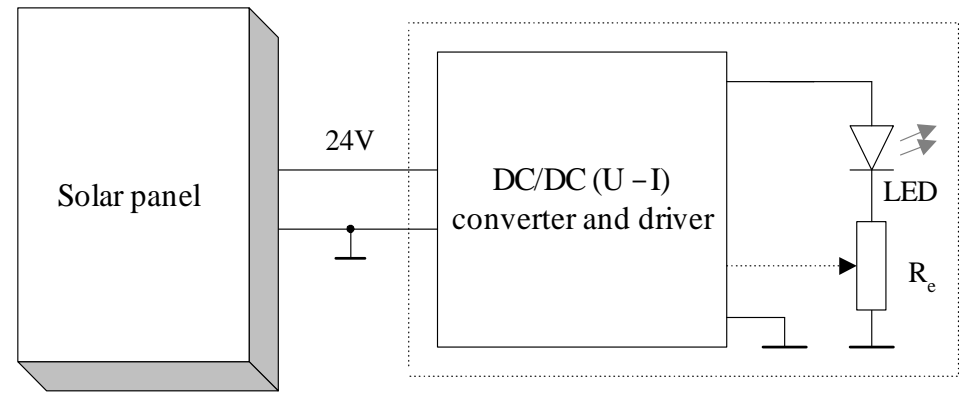

Figure 8

LED illuminator connection scheme without using current converters 
Calculation data on the received experimental values are listed in Table 2.

Table 2

Calculation efficiency data on the received experimental values

$\begin{array}{cccccc}\mathrm{P}_{1}[\mathrm{~W}] & \mathrm{P}_{2}[\mathrm{~W}] & \mathrm{P}_{3}[\mathrm{~W}] & \eta_{1} \% & \eta_{2} \% & \Sigma \eta \% \\ 27,7 & 11,1 & 5,3 & 40 & 47,8 & 20\end{array}$

Figure 8 shows the scheme of low voltage lighting connections on the basis of LEDs without voltage converters. This scheme is relevant in the sense that the voltage of energies worked out with the solar battery allows using LEDs of high power without a conversion of energy, which in turn increases the efficiency factor of the system $[6,9,10]$.

For stabilizing direct current, a self-made driver on the basis of integrated circuit PT4115 was used, its typical scheme is presented in Figure 9.

The energy-storage and provision of stable operations of the scheme can be seen in Figure 10. An additional accumulator and a controller is installed there providing the optimal charge of the energy and the desired voltage for the work of low voltage systems of lighting in Figure 11.

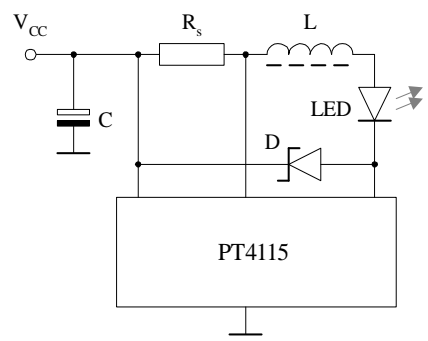

Figure 9

Scheme of current stabilization

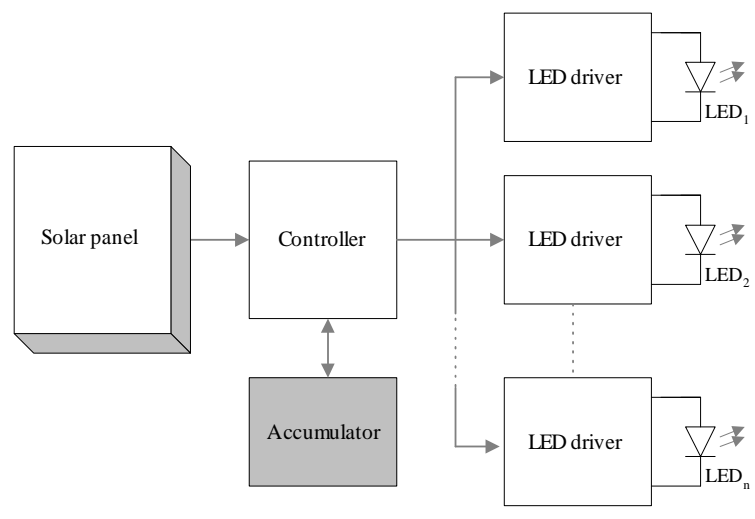

Figure 10

Scheme of low voltage systems of lighting using energy storage units 
Direct current is supplied from the solar battery in Figure 11 to the controller, which provides an uninterrupted supply of electrical power to the low-voltage lighting system simultaneously charging the accumulator [9].

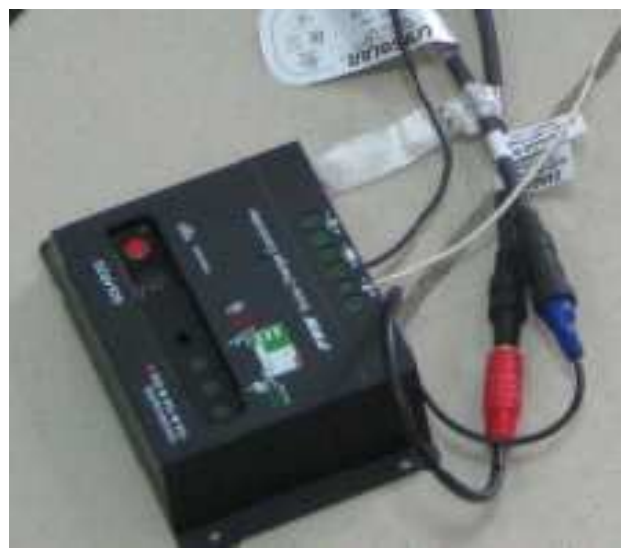

Figure 11

Charge controller of the accumulator

The scheme presented in Figure 9 was implemented for autonomous power lighting of the yurt. In this scheme, the charge controller is shown in Figure 12.

For examining the working efficiency of the system tests were carried out in situ of low voltage lighting systems using an energy storage unit, the scheme of which is shown in Figure 11.

On our national holiday in Nauryz in Ust - Kamenogorsk there was an exhibition of autonomous energy-saving technologies, where a model of real low-voltage system was presented. The photos of the realized autonomous system of lowvoltage lighting are shown in Figures 13 and 14.

Figure 12 shows the exterior appearance of the yurt, and Figure 14 shows the LED illuminators $[1,2,12]$.

Testing of the system showed its full working efficiency. The system operated autonomously over a period of seven days, while its energy consumption for lighting was only $10 \%$ of the energy generated by solar panels, that is, you could still add a load equivalent to 100 watts of electrical energy to the system.

\section{Conclusions}

The considered variants of using alternative energy sources for lighting systems show that tradition ways of their application are not effective. Double conversions of the current make the system inviable, its efficiency factor does not exceed $20 \%$. 

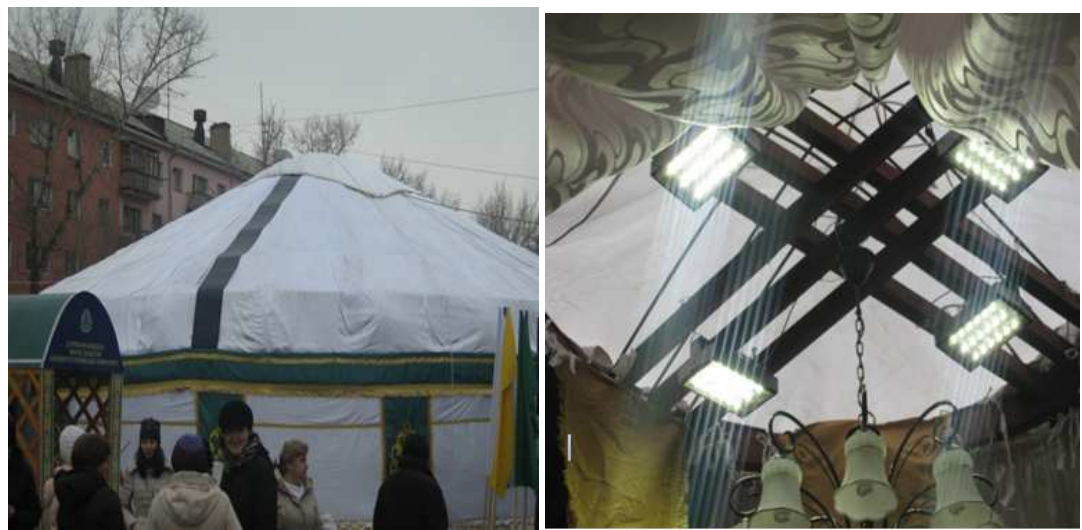

Figure 12

Exterior appearance of autonomous low voltage lighting system, and organization of operation mode of the interior lighting of the Yurt

It was demonstrated that the application of non-traditional lighting systems with voltage $24 \mathrm{~V}$ without conversion of electrical energy is more effective and less traumatic. It was also shown that at the expense of the application of energyefficient lighting systems using existing electrical wiring with no risk of overheating problems is allowed.

\section{Acknowledgement}

This research and its results as one of this article are the results of the established cooperation between D. Serikbayev East Kazakhstan State Technical University and the Óbuda University.

\section{References}

[1] S. A. Eranocyan Cetevye bloki pitaniy s vysokochactotnye preobrasovateli. M: Vysshayi

[2] S. Zarodin Promyshlennay elektronika. - M: Vysshayi shkola 2010

[3] Gyorok, Gy. Reconfigurable Control in Robust Systems by FPAA. Intelligent Systems and Informatics, 2008. SISY 2008. $6^{\text {th }}$ International Symposium on. IEEE, 2008

[4] Gyorok, Gyorgy. Embedded Hybrid Controller with Programmable Analog Circuit. Intelligent Engineering Systems (INES), $201014^{\text {th }}$ International Conference on. IEEE, 2010

[5] Gyorok, Gy. The FPAA Realization of Analog Robust Electronic Circuit. Computational Cybernetics, 2009. ICCC 2009. IEEE International Conference on. IEEE, 2009 
[6] Gy. Györök, J. Lakner. Plain Coils for PWM Application. $9^{\text {th }}$ IEEE International Symposium on Applied Machine Intelligence and Informatics, SAMI 2011 - Proceedings. Smolenice: IEEE Press, 2011. pp. 28-31 (SAMI 2011) (ISBN:9781424474301)

[7] Gy. Györök. A Special Case of Electronic Power Controll of Induction Heating Equipment. Acta Polytechnica Hungarica 11:(5) pp. 235-246 (2014)

[8] Gy. Györök, J. Lakner, M. Makó, R. Kováts. LED Displaying on Moving Mechanical Parts. IEEE $10^{\text {th }}$ Jubilee International Symposium on Applied Machine Intelligence and Informatics, SAMI 2012: Proceedings. Herlany, Szlovákia, 2012. pp. 401-404 (ISBN:978-1-4577-0197-9)

[9] A. Kvasov, A. Zhaparova, Gy. Györök. Autonomous light-emitting-diode (led) low voltage systems of light: ing integrated into smart home. $9^{\text {th }}$ International Symposium on Applied Informatics and Related Areas AIS2014. Székesfehérvár, 2014. pp. 102-106 (ISBN:978-615-5460-21-0)

[10] Károly Veszprémi, Krisztián Lamár, Accuracy Analysis of Digitally Implemented Field Orientation of Induction Motor Drive, Proceedings of the $15^{\text {th }}$ International Conference on Electrical Drives and Power Electronics EDPE 2003, Podbanské, Slovakia, pp. 497-502, 2003, ISBN 8089114454

[11] Piłat, Adam. Programmable Analog Hardware for Control Systems Exampled by Magnetic Suspension. Computer Methods and Systems (2005): $14-16$ 